\title{
Injury Prevention through Visualizing the Harc in Oil and Gas Industry, Schlumberger Asia Services Ltd.
}

\author{
Akhil K Vijayakumar, \\ PG Research Scholar, M.Tech Health, Safety and Environment, UPES, Dehradun
}

\begin{abstract}
A hazard is a potential condition which either exists or not. It may have an independent existence or exist in combination with other hazards, sometimes called events, and the conditions can lead to an actual functional failure or accident. The way this exactly happens in one particular sequence is called a scenario. Often a system has many potential failure scenarios. A hazard analysis is used as the first step in a process used to assess risk. The result of a hazard analysis is the identification of different type of hazards. It also is assigned a classification, based on the worst case severity of the end condition. Through this project, all the activities happening in the MAHAPE Base of Schlumberger were visualized, thereby making the employees aware of the hazards associated with each activity and proper control measure that can be used in-order to cope up with those hazards.Hazard Analysis and Risk Control listings were made for the whole base which covered around 28 activities such as Electrical works, all Drilling \&Measurement activities, etc. and also a draft Resource Management Plan was made. Out of 28 activities, the most severe ones were working at height, hot works like welding and mobile mechanical lifting. If the control measures proposed in the company are not implemented, the risk level is going to be catastrophic. So proper control measures are to be implemented.

[The hazards identified in the base were very risky and proper control measures were implemented to reduce the risk to acceptable level.]
\end{abstract}

Keywords: Mishap, Drilling \& Measurement, Resource Management Plan, risk level

\section{About Schlumberger}

\section{Introduction}

Founded in 1912 by French brothers Conrad and Marcel Schlumberger, Schlumberger is the world's leading supplier of technology, integrated project management and information solutions to customers working in the oil and gas industry worldwide. Employing approximately 123,000 people representing over 140 nationalities and working in more than 85 countries, Schlumberger provides the industry's widest range of products and services from exploration through production. Its principal offices are in Houston, Paris, and The Hague.

Schlumberger provides a diverse range of products and services such as Seismic oil exploration, Drilling of oil-wells, Reservoir characterization, Completion, Subsea Production, Well Intervention operations and providing Oil and Gas software solutions such asECLIPSE, INTERSECT. At the Mahape base, where the internship was undertaken, the main segments operating are Testing, D\&M, and Geo-services \& Completions while the key processes carried out are maintenance and cleaning, pressure testing and calibration using radiation of the drilling equipment

Schlumberger has a well-developed HSE program, and is committed to:

- Protect, and strive for improvement of, the health, safety and security of employees at all times

- Eliminate Quality non-conformances and HSE accidents

- Meet specified customer requirements and ensure continuous customer satisfaction

- Set Quality \& HSE performance objectives, measure results, assess and continually improve processes, services and product quality, through the use of an effective management system

- Plan for, respond to and recover from any emergency, crisis and business disruption

- Minimize our impact on the environment through pollution prevention, reduction of natural resource consumption and emissions, and the reduction and recycling of waste

- Apply technical skills to all HSE aspects in the design and engineering of our services and products

- Communicate openly with stakeholders and ensure an understanding QHSE policies, standards, programs and performance. Reward for outstanding QHS performance

- Improve performance on issues relevant to stakeholders of global concern and share with them knowledge of successful QHSE programs and initiatives 
About the Project

[Introduction to HARC, Visual HARC, Resource management]

[HARC Description

- Identify possible hazards

- Provide an evaluation of the risks

- Prompt alternative design solutions to mitigate or control the risks to an acceptable level

- Defines criteria for decision making

- Focuses on the relationship between the worker, the task, the tools, and the work environment]

\section{[VISUAL HARC}

It is the visual representation of the HARC, portraying:
1. ACTIVITY
2. HAZARDS
3. CONTROL MEASURES]

\section{Objectives}

1. To understand and comply by the Schlumberger HSE Management System and the HSE Policy

2. To study the hazards in the whole base, the risks associated with it and methods to reduce those risks

3. To prepare Mahape PPE assessment HARC

4. To prepare a HARC for all contractor activities

5. To prepare a Visual HARC and display it in the work premises

\section{Deliverables}

1. Study various segments in Mahape Base with respect to the activities taking place and hazards associated with it

2. Prepare a HARC in which PPE is assessed

3. Prepare another HARC in which all the contractor activities are assessed

4. Considering those HARCs and assessing the real-time activities, prepare a Visual HARC

5. Display those visual HARCs in the work premises

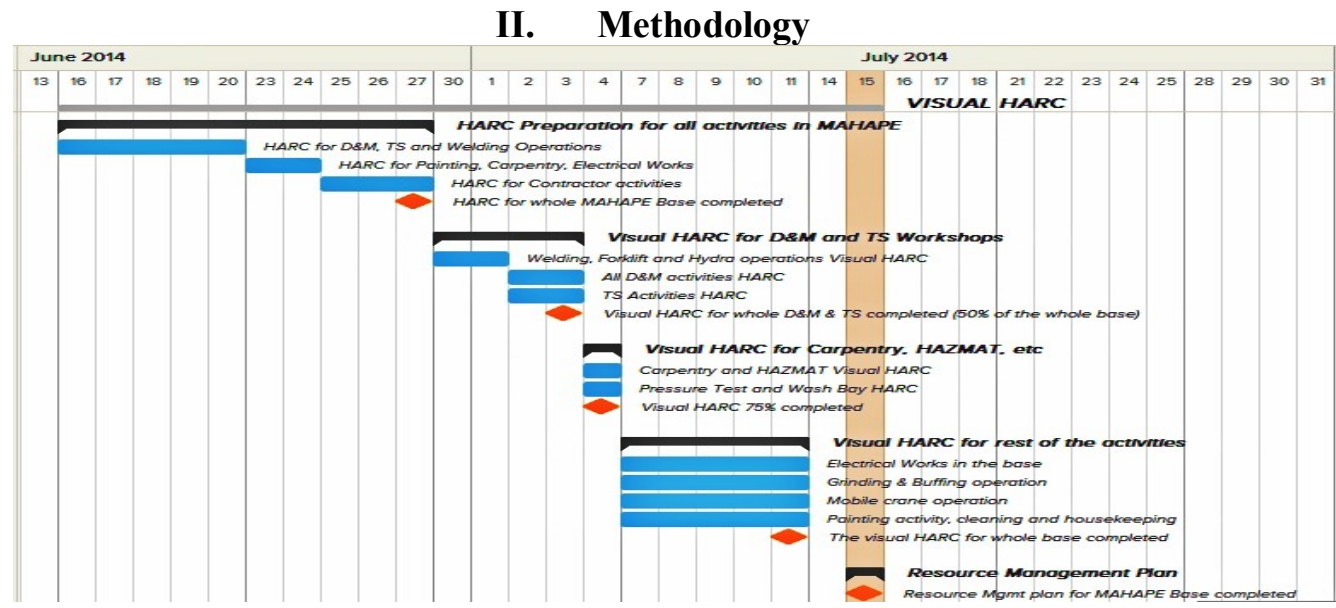

HARC

- Formed a team;

- Selected key tasks/processes;

- Defined Activities happening in the base;

- Identified Risks \&proposed Risk Controls;

- $\quad$ Assessed the Residual Risk;

- HARC developed with risk control measures and got approved

\section{Visual HARC}

Prepared 23 Visual HARC covering whole MAHAPE Base

- All D\&M and TS activities

- Welding, Wash bay and Pressure Test bay

- Grinding, buffing, HAZMAT handling 
- Forklift, Hydra and Mobile Crane

- Carpentry, Painting, Electrical and Cleaning \& Housekeeping

\section{Resource Management}

- Collected data for Resource Management Plan and made a draft RMP for the base

Key Points Regarding HARC

- Fosters holistic and comprehensive understanding of hazards and controls for a process

- Emphasis on control not detection

- Reduce possibility of risks and surprise costs

- Lots of paper work

- Nobody takes care to read it

- Difficulty in effective communication

\section{Key Points of Visual HARC}

* Presented through live pictures which were taken while employees \& contractors were working in MAHAPE Base

* Greater level of acceptance

* Involvement of contractors more lively

* Reliable way of communicating control measures

- Even minute hazards present could be identified

* Control measures in pictures make employees and contractors feel it's doable

Posted 43 Visual HARC in bigger size across whole MAHAPE Base

Two projects HARC Record form and Visual HARC were implemented in the base after getting approval from HSE Manager and Facility Manager.

- Collected data for Resource Management Plan and made a draft RMP for the base

\section{Conclusion}

There are many advantages if we implement Visual HARC in any Base or work premises:

- Easy mode of communication through pictures

- Greater acceptability

- Involvement of contractors more lively

- Reliable way of communicating control measures

- Even minute hazards present could be identified

- Control measures in pictures make workers feel doable

In the organization, the effect of performance is driven by three things: human, money and law. So safety is not only protecting the persons physically but its benefits are also for the companies, as they need not to spend extra money to recover the unwelcome accidents happen.

Hence, it can be concluded that organization should be committed to safe practices in all of its operation \& maintenance activities. The Health \& Safety measures are implemented in order to prevent the risk of work-related incidents and to facilitate the intervention of those concerned during working on job site. Health \& Safety law requires employers to look after the health, safety and welfare of their employees. HSE affects work, and persons related to that work for example clients, contractors and visitors to their premises. Employers also have a duty to identify, assess and control safety risks.

[1]. Dynamic capabilities in the upstream oil and gas sector: Managing next generation competition- Amy Shuen, Paul F. Feiler, David J. Teece- May-2014

[2]. Safe use of work equipment. Provision and Use of Work Equipment Regulations 1998. Approved Code of Practice and guidance L22 (Second edition) HSE Books 1998 ISBN 0717616266

[3]. Electricity at work: Safe working practices HSG85 (Second edition) HSE Books 2003 ISBN 0717621642

[4]. Schlumberger internal reference document - Environmental management Standard - SLB-QHSE-S008

[5]. A conceptual framework and practical guide for assessing fitness-to-operate in the offshore oil and gas industry - Mark A. Griffina, Melinda R. Hodkiewicza, Jeremy Dunsterb, LisetteKansea,Katharine R. Parkesa,c, DannielleFinnertya, John L. Corderya, Kerrie L. Unsworth- December 2013

[6]. Research on FTA of fire and explosion in the crude oil gathering- transport combination station- XUE Zhao-mei- Safety Engineering Major, School of Electronic Engineering, Xi'an Shiyou University, Shaanxi Province, Xi'an 710065, China- 2011 
[7]. 2012 International Symposium on Safety Science and TechnologyRisk quantitative calculation and ALOHA simulation on the leakageaccident of natural gas power plant- SHAO Hui**, DUAN Guoning- Department of Environment and Safety Engineering, Changzhou University, Changzhou 213164, Jiangsu, China- 2012

Abbreviations

a. HARC- Hazard Analysis and Risk Control

b. HSE- Health, Safety and Environment

c. QHSE- Quality, Health, Safety and Environment

d. PPE- Personal Protective Equipment

e. HAZMAT- Hazardous Materials

f. D\&M- Drilling \& Measurements

g. TS- Testing Services

h. RMP- Resource Management Plan 